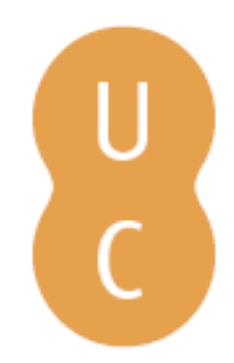

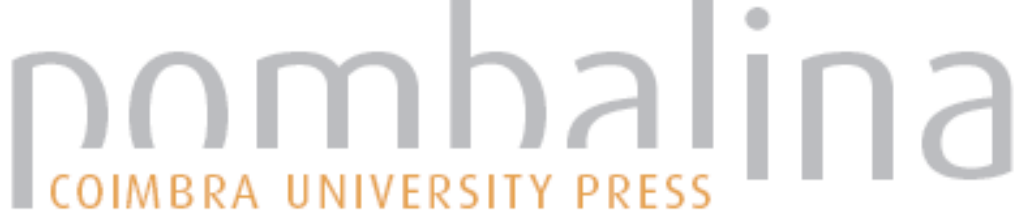

\section{As narrativas digitais na formação docente: entre o proposto e o realizado}

\author{
Autor(es): $\quad$ Lostada, Lauro Roberto; Cruz, Dulce Márcia
}

Publicado por: Imprensa da Universidade de Coimbra

URL

persistente: URI:http://hdl.handle.net/10316.2/47383

DOI: $\quad$ DOl:https://doi.org/10.14195/978-989-26-1716-9_7

Accessed : $\quad$ 26-Apr-2023 10:35:55

A navegação consulta e descarregamento dos títulos inseridos nas Bibliotecas Digitais UC Digitalis, UC Pombalina e UC Impactum, pressupõem a aceitação plena e sem reservas dos Termos e Condições de Uso destas Bibliotecas Digitais, disponíveis em https://digitalis.uc.pt/pt-pt/termos.

Conforme exposto nos referidos Termos e Condições de Uso, o descarregamento de títulos de acesso restrito requer uma licença válida de autorização devendo o utilizador aceder ao(s) documento(s) a partir de um endereço de IP da instituição detentora da supramencionada licença.

Ao utilizador é apenas permitido o descarregamento para uso pessoal, pelo que o emprego do(s) título(s) descarregado(s) para outro fim, designadamente comercial, carece de autorização do respetivo autor ou editor da obra.

Na medida em que todas as obras da UC Digitalis se encontram protegidas pelo Código do Direito de Autor e Direitos Conexos e demais legislação aplicável, toda a cópia, parcial ou total, deste documento, nos casos em que é legalmente admitida, deverá conter ou fazer-se acompanhar por este aviso. 

LAURO ROBERTO LOSTADA

Assistente Técnico Pedagógico na Escola de Educação Básica Irmã Maria Teresa.

lostada25@yahoo.com.br

DULCE MÁRCIA CRUZ

Universidade Federal de Santa Catarina (UFSC)

dulce.marcia@gmail.com

\section{AS NARRATIVAS DIGITAIS NA FORMAÇ ÃO DOCENTE: ENTRE O PROPOSTO EO REALIZADO}

\section{Introdução}

A evolução das mídias tem gerado uma nova gama de elementos de escrita, possibilitando a agregação de múltiplos mecanismos digitais, que permitem grandes inovações na produção do conteúdo, no compartilhamento das informações e na criação das redes sociais. Assim sendo, a formação de professores tem se mostrado uma necessidade pungente em nossa sociedade, afinal, as práticas escolares por muito tempo reproduziram um modelo acrítico de ensino, cujo sucesso estava diretamente ligado à mera capacidade de memorização. Ler, no mundo contemporâneo, exige uma nova relação com o conhecimento e a participação dos sujeitos enquanto atores só é possível a partir da capacidade crítica e criativa de leitura e escrita das múltiplas linguagens que permeiam o social.

As transformações que as tecnologias implicaram na sociedade acabaram por inaugurar uma cultura em que o aprendizado passa a ser menos fundado na dependência dos adultos que na própria exploração que os jovens fazem por si mesmos do novo universo tecnocultural que os envolvem (Martín-Barbero, 2004). A questão é que este novo cenário pré-figurativo provoca a escola, segundo Martín-Barbero (2004), pois ela reluta em ceder às mudanças, incapaz que é de ressignificá-las, produzindo e aumentando uma profunda 
lacuna entre aquilo que os jovens vivenciam e o que aprendem em suas salas de aula, deixando-os, de certa forma, indefesos ante as novas tecnologias e impedindo que delas possam se apropriar de forma crítica e criativa.

Embora a escola tenha privilegiado ao longo da sua história a leitura da palavra escrita como eixo norteador das suas propostas de ensino, ela se vê diante do difícil desafio de rever suas práticas para que os alunos aprendam a ler todas as novas possibilidades performáticas da linguagem (oral, escrita, sonora e imagética). Mais do que uma mera leitura de novos signos linguísticos, contudo, a alfabetização midiática consiste em capacitar o sujeito para que possa compreender o mundo e compreender-se no mundo.

Assim, podemos ler em Freire (1988, p. 10-12):

A leitura do mundo precede a leitura da palavra, daí que a posterior leitura desta não possa prescindir da continuidade da leitura daquele. A linguagem e a realidade se prendem dinamicamente. A compreensão do texto a ser alcançado por sua leitura crítica implica a percepção das relações entre o texto e o contexto.

Vivemos num complexo cenário cultural que evidencia a crise da educação, através do aprofundamento do abismo que se estabelece diante daquilo que os jovens vivenciam e o que lhes ensinam as escolas. De modo geral, os professores reproduzem em suas práticas um modelo educacional que se tece em torno do binômio saber/poder, consolidando um esquema de produção de conhecimento que gira permanentemente em torno da figura docente e daqueles a quem ela representa. Diante das novas tecnologias e de um aluno mergulhado num mundo abundante de informações, a reação da escola parece ser a de um entrincheiramento em seu próprio discurso e práticas. Afinal,

enquanto o ensino percorre o âmbito do livro, o professor se sente forte, mas quando aparece o mundo da imagem o professor balança, a terra se move: porque o aluno sabe muito mais e, sobretudo, maneja melhor as linguagens da imagem que o professor (Martín-Barbero, 2004, p. 343).

A escola, corporificada nas práticas de seus professores, mantém o saber como fonte de poder e, neste sentido, desde suas origens, faz uso de suportes 
miméticos que permitam internalizar e reproduzir fielmente comportamentos arquetípicos (Cruz Junior, 2017). O que precisa ser refletido a partir dessa realidade é uma reforma educacional que possa dar conta de uma segunda alfabetização, justamente aquela ligada às múltiplas leituras que hoje conformam o ciberespaço.

Essas mudanças que os meios digitais vêm provocando trazem a emergência de novos e diferentes modos de circulação da comunicação, suas mensagens e linguagens (verbal, imagética, musical, corporal, gráfica, etc.) que precisam ser aprendidas pelos professores. Se somadas à rapidez, fluidez e plasticidade da escrita e leitura dos gêneros digitais em que circulam (chats, blogs, Twitter ou Facebook, dentre outros), essas linguagens suscitam e acolhem práticas sociais, modos de uso, consumo, apropriação e produção de informação que se reconfiguram em novos espaços e eventos a partir de habilidades e competências que são exigidas para a operação dessas tecnologias (Cruz, 2013).

Os elementos narrativos da cultura digital são introduzidos nesse cenário de forma calculada, quase sempre apenas para tornarem mais atrativas as aulas, cujo fundamento persiste centrado na palavra escrita e/ou proferida (Martín-Barbero, 2004). Assim sendo, os alunos não são devidamente capacitados para a leitura das múltiplas linguagens e sua aprovação permanece sendo condicionada à reprodução de conceitos, sem que lhes seja oferecida uma formação crítica e criativa de que necessitam para lidar com o mundo que os circundam.

Dentre as iniciativas do governo brasileiro para promover uma formação para o uso pedagógico das mídias na rede pública de ensino, a mais relevante é a do Programa Nacional de Tecnologia Educacional (Proinfo), criado em 1997 (Cruz, 2015). Depois de várias iniciativas, em 2014, buscando alcançar uma integração da formação para as mídias com o cotidiano das escolas, foi criada dentro do Proinfo Integrado, a Especialização em Educação na Cultura Digital, visando envolver não apenas professores, mas também gestores e multiplicadores dos núcleos de tecnologia educacional de estados e municípios do país (Cruz, 2015). O projeto se baseia na construção de narrativas digitais como principal produtor de aprendizagem, centrando a "organização dos materiais de formação em relatos de experiências pedagógicas trans- 
formadoras onde se privilegie a narrativa dos seus protagonistas (cenários)" (Ramos et al., 2013, p.15).

A partir dessa proposta do curso foi possível levantar algumas questões: Como foram produzidas essas narrativas digitais nos diferentes espaços do curso? Como estudar essas narrativas digitais? Poderão ser percebidas mudanças na cultura digital e nas práticas pedagógicas por parte dos professores em termos de ampliação dos seus letramentos? Essas questões constituem o foco de uma pesquisa mais ampla que foi iniciada em 2015 para acompanhar a oferta da especialização e que está em andamento.

No âmbito deste capítulo, o que se vai narrar são os resultados parciais da pesquisa que buscou inicialmente verificar se o paradigma do texto escrito foi superado na exposição dos conteúdos e se os cursistas tiveram um parâmetro para a produção de práticas pedagógicas baseadas em narrativas multimodais adequadas às novas linguagens, habilidades e competências da cultura digital.

A importância do tema que justifica este estudo está relacionada às críticas feitas ao Proinfo de que, mesmo tendo oferecido formação para um grande número de professores em duas décadas, seus esforços não resultaram nem em uma mudança significativa das práticas pedagógicas nem em uma popularização de novas metodologias que aproveitassem os laboratórios e equipamentos distribuídos pelo governo para a rede pública de ensino. Neste sentido, Basniak e Soares (2016, p. 211) afirmam que, apesar do esforço dessas políticas de inclusão, ainda não se efetivou uma formação de professores para as tecnologias que traga efetivamente mudanças reais na qualidade das aulas das escolas públicas brasileiras, de modo que "as tecnologias sejam ferramentas de emancipação dos estudantes e não se constituam como mais um agravante de exclusão social". Os autores descrevem algumas das causas dessa dificuldade:

Em muitos casos, falta proporcionar condições para que os professores possam participar de formações em seu horário de trabalho, motivando seu aperfeiçoamento constante, a fim de que reflitam sobre suas práticas pedagógicas e nelas incorporem o uso de recursos tecnológicos. Muitas formações se caracterizam mais por cursos esporádicos e pontuais que por programas contínuos, dessa forma, entendemos que não se constituem em formação continuada, mas sim em capaci- 
tações superficiais que buscam instrumentalizar os professores no uso dos recursos tecnológicos, sem possibilitar a reflexão e a mudança na prática dos professores e consequente inovação de seu trabalho (Basniak \& Soares, 2016, p. 211).

Por essas razões, a inovação que este capítulo traz é a de analisar este curso de formação docente, suas intenções e sua realização a partir de seus materiais didáticos. Dessa forma, busca contribuir para conhecer melhor o projeto, que envolveu em sua produção os mais renomados pesquisadores e suas instituições e que, pelo grande investimento feito em recursos humanos e materiais, representa uma proposta inovadora, que ainda não foi suficientemente analisada (Lostada \& Cruz, 2017). Assim, avaliar o projeto desenvolvido no Curso de Especialização em Educação na Cultura Digital pode levantar indícios do que melhorar nas novas ofertas de formação, atreladas ou não ao Proinfo, para que possam alcançar maior eficiência em relação à ampliação dos letramentos digitais de professores.

\section{Metodologia}

O Curso Superior de Especialização em Educação na Cultura Digital teve como objetivo formar educadores para integrar crítica e criativamente as tecnologias digitais de comunicação e informação aos currículos escolares (Ramos, 2013). Segundo o documento base do projeto (Ramos, 2013), o curso tinha como meta constituir um diálogo ativo na busca por mudanças de paradigma na educação, organizando-se com base no compartilhamento de experiências que exploram, demonstram e analisam as possibilidades criativas da integração das Tecnologias Digitais de Informação e Comunicação (TDIC) aos currículos escolares.

Em Santa Catarina, especificamente, a Universidade Federal de Santa Catarina (UFSC) foi a instituição encarregada da oferta do curso na modalidade a distância - com 800 vagas disponibilizadas para instituições das redes municipais e da rede estadual, com limite de até 100 escolas para cada rede. Nessas escolas poderiam se inscrever os educadores que estivessem atuando nas funções de professores, gestores ou formadores de núcleos de tecnologia. 
Embora o curso fosse planejado na modalidade a distância, ele também previa até $20 \%$ de sua carga horária na modalidade presencial, a ser realizada nas escolas e na própria UFSC (Ramos, 2013).

O ciclo completo do curso desenvolveu-se em um período de dezoito meses, com duração mínima de 360 horas, o que correspondia a aproximadamente seis horas de estudos semanais. Os materiais didáticos, elaborados por equipes de conteudistas de diversas instituições de ensino superior do país, foram distribuídos exclusivamente em formato digital, como documentos hipertextuais em diversos suportes midiáticos (vídeos, textos, animações, entre outros), disponibilizados no ambiente virtual de ensino e aprendizagem denominado e-Proinfo (http://e-proinfo.mec.gov.br/), criado e mantido pelo Ministério de Educação (MEC). Mesmo após a conclusão da oferta, é possível percorrer todo o curso, acessando cada um de seus módulos através de um website (http://educacaonaculturadigital.mec.gov.br/). A estruturação modular do curso permite que, por adesão, sejam ofertadas novas etapas da formação, de modo customizado e adaptado às necessidades de cada oferta. Uma versão completa dos módulos também podia ser baixada como aplicativo para dispositivos móveis através do Google Play Store.

Para estudar os materiais didáticos, os pesquisadores optaram por realizar uma análise tanto dos conteúdos e atividades propostas como das realizadas no curso, considerando que a metodologia adotada pode permitir a exposição das matrizes político-pedagógicas do projeto. A estratégia, embora não ofereça um diagnóstico completo sobre as práticas de letramento digital adotadas no curso, possibilita um acesso aos nortes do projeto, como porta de entrada para novas pesquisas.

Num primeiro momento, os pesquisadores tiveram acesso ao conteúdo do curso através de ingresso público, a partir do qual se pôde elaborar um mapa cartográfico do projeto e suas matrizes narrativas. Em seguida, obteve-se dos responsáveis pela coordenação do projeto na Universidade Federal de Santa Catarina um acesso detalhado aos módulos através de um perfil docente, que permitia a visualização de cada um dos módulos do curso e também das participações dos cursistas em cada uma das atividades solicitadas. Vale lembrar, neste sentido, que o curso foi desenvolvido no formato modular como um mecanismo mais eficiente de formação interdisciplinar, permitindo que os 
professores das diversas áreas pudessem percorrer uma trilha pedagógica que lhes possibilitaria dar suporte para o desenvolvimento de novos letramentos (Ramos, 2013).

\section{Resultados e Análises}

Um levantamento inicial do curso permitiu elaborar um mapa dos elementos narrativos, ou seja, dos recursos que foram utilizados ao longo do projeto como ferramentas facilitadoras para a capacitação docente para o uso das mídias em sala de aula. Tais elementos podem ser vistos no gráfico abaixo:

GRÁfICO 1: Elementos Narrativos do Curso de Especialização em Educação na Cultura Digital - Eixo de Conteúdos

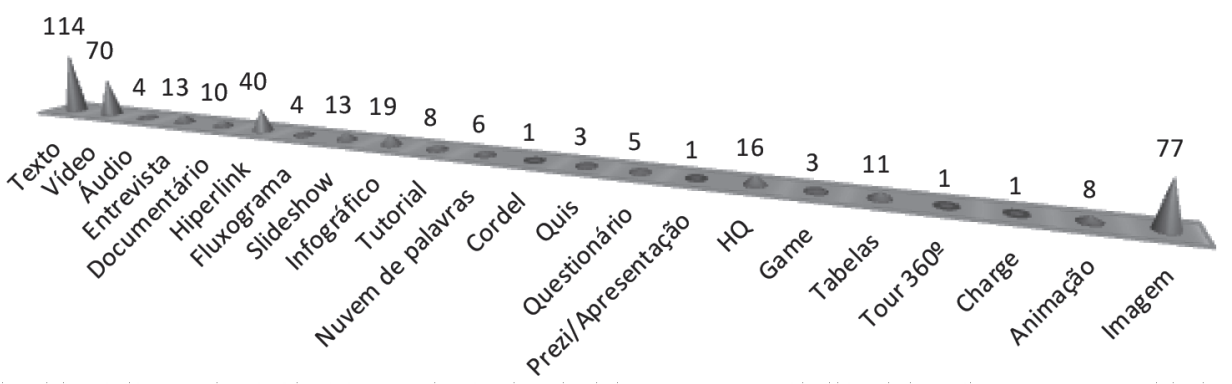

Fonte: Dos autores (2017)

A análise do gráfico mostra que, apesar da intenção do projeto de constituir uma formação docente apoiada no compartilhamento de experiências que exploram, demonstram e analisam as possibilidades criativas da integração das Tecnologias Digitais de Informação e Comunicação (TDIC) aos currículos escolares (Ramos, 2013), o curso se estruturou, no tocante aos conteúdos, a partir de quatro grandes eixos narrativos, a saber: o texto, a imagem, o vídeo e o hiperlink. Com isso, é possível afirmar que, diante das diversas outras possibilidades narrativas existentes no cenário atual das tecnologias educacionais, a escolha foi pela manutenção dos suportes que dão corpo às bases epistemológicas que, há séculos, sustentam o modelo educacional, com a inclusão de algumas ferramentas digitais. Ou seja, muitos dos elementos narrativos utilizados ao longo do curso constituem-se como atrativos para 
uma formação baseada essencialmente na palavra escrita e/ou proferida pelo professor formador, como diria Martín-Barbero (2004).

Os nortes narrativos multimodais que talvez pudessem enfatizar um avanço didático quanto ao uso das mídias no projeto de formação estruturado pelo curso acabaram sendo pouco explorados nos diversos módulos. Abaixo, por exemplo, são apresentados alguns gráficos onde se evidenciam exemplos da falta de variação narrativa, apesar das diversas possibilidades que os eixos temáticos dos módulos permitiam.

GRÁfICO 2: Exemplos de Elementos Narrativos por Módulo Temático - Eixo de Conteúdos

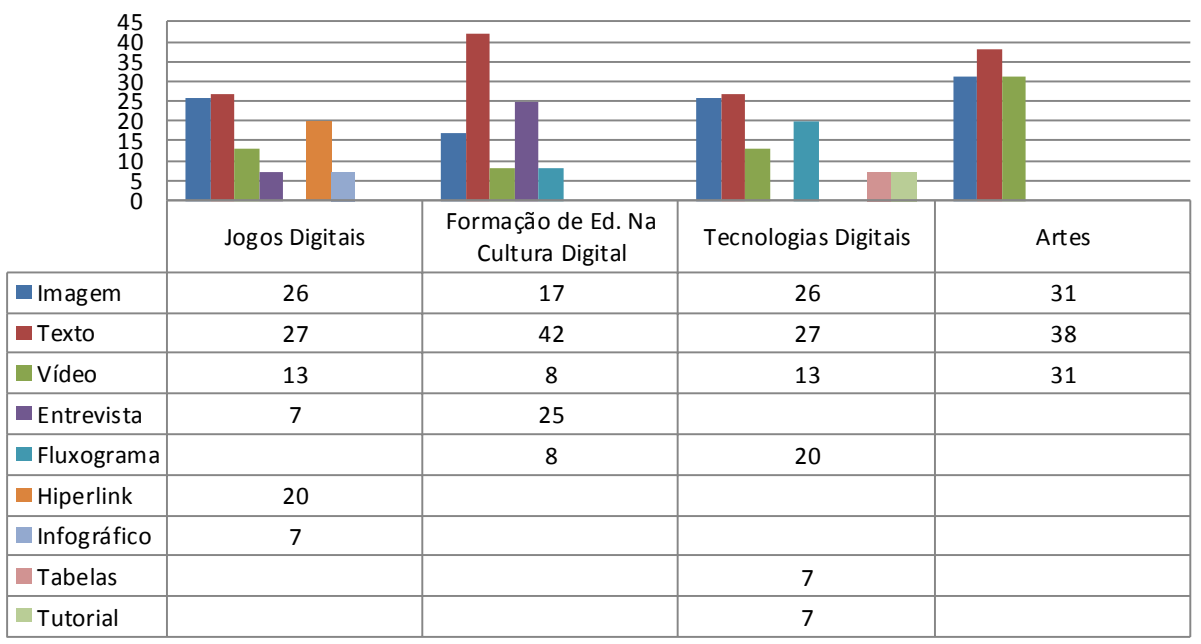

Fonte: Dos autores (2017)

No módulo de Jogos Digitais, a título de exemplo, não foram encontradas quaisquer aplicações gamificadas do conteúdo apresentado, ou seja, a aprendizagem por jogos não foi utilizada nem mesmo no módulo que teria como função analisar esta possibilidade didática. Em geral, todo o curso foi estruturado fundamentalmente a partir de textos, imagens, vídeos e hiperlinks. Ao contrário do que se poderia esperar, os únicos módulos que fizeram uso do recurso da gamificação foram os de Língua Portuguesa, Geografia e História - nesses módulos os alunos foram convidados a jogar e, através da aplicação, 
compreender novos conceitos e possibilidades metodológicas para o ensino da disciplina.

Também nos módulos de Formação de Educadores na Cultura Digital, Tecnologias Digitais e Artes, houve a manutenção de uma base metodológica centrada no texto, na imagem e no vídeo. Esse padrão poderia, aliás, ter sido apresentado para qualquer um dos outros módulos do curso, mas optamos por destacar nesta análise apenas esses quatro, por considerá-los tematicamente representativos em relação a uma pedagogia mais ativa, cuja matriz representaria o universo da cultura digital que se pretendia fomentar com a proposta do curso (Ramos, 2013).

Seguindo adiante com a proposta da pesquisa, após a análise dos conteúdos do curso, passamos ao exame também das atividades solicitadas e daquelas efetivamente realizadas pelos alunos ao longo da sua formação. É importante destacar que o curso oferecia uma série de atividades como "sugestões" aos professores responsáveis pelos módulos, que, juntamente com seus tutores, teriam a tarefa de selecionar o que considerassem mais pertinente para aplicação com seus alunos. Deste modo, apresentamos abaixo dois gráficos, a partir dos quais é possível traçar um comparativo entre as atividades planejadas e as praticadas. As atividades planejadas pelos autores do curso estão no Gráfico 3:

GRÁfICO 3: Atividades Propostas

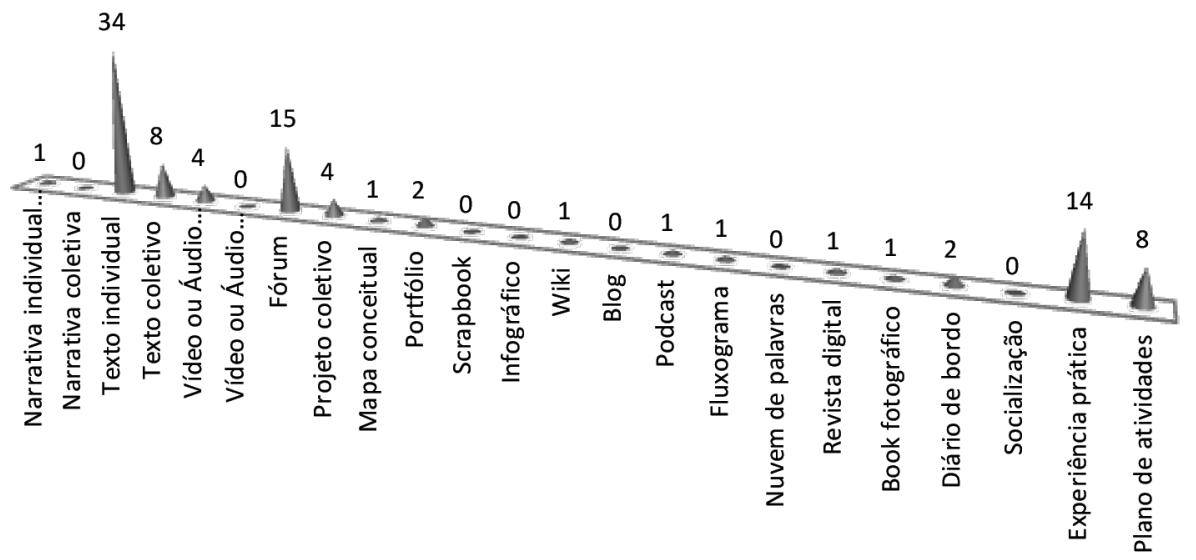

Fonte: Dos autores (2017). 
No Gráfico 4 estão representadas as atividades escolhidas pelos professores ministrantes para serem realizadas pelos cursistas:

GRÁFICO 4: Atividades Realizadas

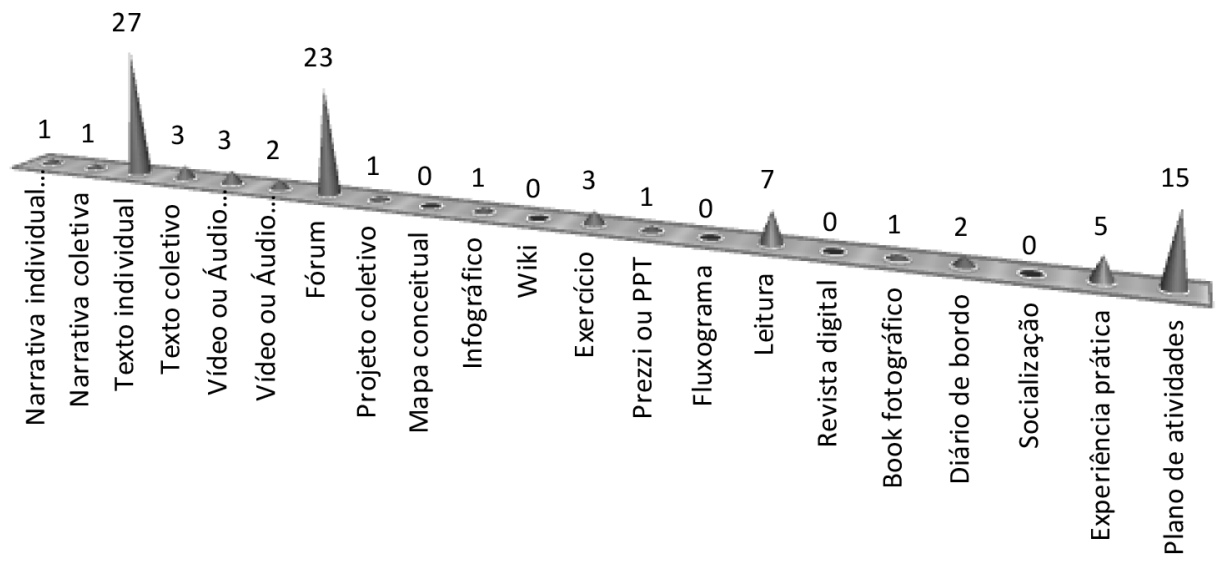

Fonte: Dos autores (2017).

A comparação dos gráficos acima permite concluir que o curso, no seu eixo de conteúdo, se organizou em torno de alguns poucos elementos narrativos, a saber: o texto individual, o fórum, a experiência prática e o plano de atividades. O modelo do curso seguiu, portanto, um parâmetro tradicional de formação segundo o qual os estudantes desenvolvem boa parte de suas atividades de maneira isolada, fragmentada, tendo poucos momentos de socialização. Teve a predominância de um conjunto de procedimentos desenvolvidos exclusivamente para que os professores se agregassem, mesmo sem motivação própria, para desenvolver uma determinada atividade, na maioria das vezes caracterizantes de uma verdadeira colegialidade forçada, como nas palavras de Hargreaves (2001).

A seguir, também a título de exemplo, trazemos um quadro que apresenta as atividades propostas e aquelas realizadas pelos alunos no módulo de Formação de Educadores na Cultura Digital: 
GRÁfICO 5: Atividades Propostas x Atividades Realizadas

- Módulo Formação de Educadores na Cultura Digital

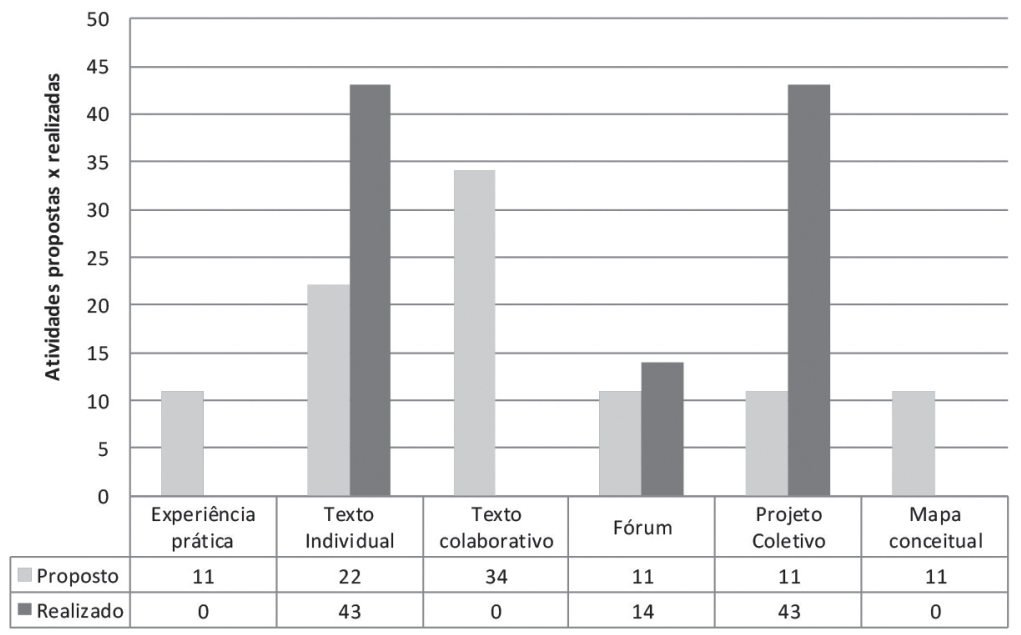

Fonte: Dos autores (2017)

Se compararmos o que foi proposto nos módulos com aquilo que se realizou de fato ao longo do curso poderemos evidenciar a divergência metodológica de um projeto formativo que, por sua natureza, tenderia à multiplicidade de linguagens e estratégias narrativas. Essa é a questão mais importante que emerge da avaliação do módulo de Formação de Educadores na Cultura Digital, que aqui representa de forma mais incisiva o contraste que se pretende evidenciar na pesquisa: afinal, como formar educadores para a cultura digital sem se utilizar das inúmeras possibilidades narrativas que essa cultura permite e incentiva?

Por outro lado, vale ressaltar que, de modo geral, as críticas aqui mensuradas sobre as carências do projeto não o desqualificam por completo, afinal, o curso seguiu como uma importante oportunidade para que os professores das redes de ensino repensassem suas práticas pedagógicas. Neste sentido, configurou-se como uma excelente oportunidade para que os professores, mais do que aprendessem a utilizar das tecnologias como instrumentos para uma melhor prática docente, pudessem se organizar coletivamente em suas escolas em vista de um objetivo comum. Como podemos ler em Cerny et al. (2014, p. 1.344): 
Garantir que os sujeitos da aprendizagem sejam produtores e autores dos conteúdos digitais, nas várias mídias e linguagens digitais disponíveis, é outro desafio que os programas de formação precisam assumir mais intensamente já nos níveis iniciais e básicos, e não apenas nos níveis de especialização mais avançados. As formações, portanto, deverão propiciar aos professores produzirem seus próprios projetos e conteúdos, individual ou coletivamente, e incentivar a produção dos alunos nas diferentes mídias, de forma articulada à proposta pedagógica e aos currículos escolares.

Pelo que foi possível observar através da pesquisa, o curso serviu como incentivo à cultura da colaboração docente (Hargreaves, 2001), ao organizar grupos de trabalhos em cada uma das escolas participantes do projeto (a inscrição foi condicionada à existência de, no mínimo, quatro professores e dois gestores interessados em participar do curso na mesma unidade de ensino). O que se constatou, em resumo, foi a existência de um esforço conjuntural em vista de uma cultura de colaboração capaz de gerir espaços de discussão nos ambientes escolares, promovendo a busca de alternativas para os problemas locais no que concerne à inclusão de uma nova cultura escolar, baseada fundamentalmente na participação.

\section{Conclusão}

Este capítulo discutiu como o Curso de Especialização em Educação na Cultural Digital, do Proinfo Integrado, foi constituído enquanto projeto de formação continuada para professores da educação básica com vistas ao uso das diversas possibilidades midiáticas disponíveis. Oferecido a distância, para aproximadamente 800 profissionais da educação do estado de Santa Catarina, no sul do Brasil, o curso teve como objetivo incentivar a construção de narrativas digitais e sua aplicação na prática da escola. Para investigar se os materiais didáticos do curso refletiram esse objetivo, o propósito deste capítulo foi o de verificar se o paradigma do texto escrito foi vencido na exposição dos conteúdos e se os cursistas tiveram um parâmetro para a produção de práticas pedagógicas baseadas em narrativas multimodais adequadas às novas linguagens, habilidades e competências da cultura digital. 
A maneira escolhida para isso foi analisar todos os módulos de forma quantitativa para levantar por um lado, qual foi o tratamento multimodal dos conteúdos nos materiais didáticos e, por outro, quais narrativas digitais estavam previstas no material básico e quais foram efetivamente escolhidas pelos ministrantes para serem produzidas pelos estudantes. Uma aproximação quantitativa dos conteúdos indicou que o curso se estruturou em quatro eixos narrativos: texto, imagem, vídeo e hiperlink, com pouca variação, apesar das possibilidades que as temáticas dos módulos permitiam, sendo que a base metodológica da produção de narrativas foi centrada na maioria dos módulos quase que exclusivamente em atividades de produção de texto, com alguma intercorrência no uso de imagem e vídeo. Com isso, parece que o objetivo inicial do projeto acabou não sendo atingido, pois as bases curriculares foram desenvolvidas através dos mesmos mecanismos narrativos que se pretendia superar, sem que novas possibilidades fossem apresentadas como parâmetro para os professores. Assim, a formação de professores no caso estudado seguiu um modelo de ensino ligado à capacidade de memorização e reprodução, num mundo que exige cada vez mais sujeitos ativos, com capacidade crítica e criativa de leitura e escrita das múltiplas linguagens que permeiam o social.

Tendo em vista que as novas práticas midiáticas e seus letramentos vêm gerando uma gama de elementos de escrita com múltiplos mecanismos digitais, que permitem grandes inovações na produção do conteúdo, no compartilhamento das informações e na criação das redes sociais, o curso aqui analisado não obteve êxito em superar o paradigma do texto escrito. Mesmo tendo permitido o desenvolvimento de ambientes de aprendizagem colaborativa através de narrativas textuais e incentivado os professores a tecer novas relações cognitivas entre seus colegas e tecnologias, essa possibilidade, no entanto, numa primeira análise qualitativa, careceu de uma complexidade maior em sua proposta aplicada.

No entanto, para traçar uma conclusão mais acurada sobre o quanto a escrita nesses ambientes colaborativos ampliou o letramento midiático dos cursistas é preciso incluir novos elementos de investigação.

Neste sentido, as questões que fazem parte do projeto mais amplo se mantêm: Como serão produzidas essas narrativas digitais nos diferentes espaços do curso? Como estudar essas narrativas digitais? Poderão ser percebidas 
mudanças na cultura digital e nas práticas pedagógicas por parte dos professores em termos de ampliação dos seus letramentos?

O estudo indicou que, a partir dessas perguntas, é possível traçar alguns novos caminhos de investigação. Por um lado, seria relevante realizar um estudo detalhado e comparativo das diferenças entre os módulos e da adequação ou não de seus materiais didáticos e atividades pedagógicas previstas e realizadas à luz dos objetivos de aprendizagem específicos de cada um deles. Por outro lado, a análise das narrativas elaboradas pelos cursistas nos diferentes espaços virtuais de produção dos módulos poderia verificar se houve ampliação dos seus letramentos, com a inclusão ou não de novos recursos multimodais. De qualquer modo, para estas duas vertentes de investigação, seria preciso criar um instrumento mais refinado de análise teórico-metodológica que permitisse compreender melhor as linguagens e seus produtos midiáticos enquanto recursos com finalidade educacional.

Apontar essas possibilidades e necessidades pode ser uma das contribuições desta pesquisa que tinha como meta apenas uma análise documental que pudesse servir para um mapeamento do projeto, onde fosse possível refletir inicialmente e de maneira exploratória a formação docente para as novas linguagens. Nestes termos, alcançamos nosso objetivo ao identificar os nortes narrativos do curso, cujos elementos acabaram apontando para um modelo de formação aparentemente ainda incapaz de capacitar os professores participantes para incluir as novas linguagens em suas práticas docentes. Seguir investigando essas conclusões parciais parece ser uma tarefa frutífera e útil.

\section{Referências bibliográficas}

BASNIAK, M.; \& Soares, M. (2016, maio/agosto). O ProInfo e a disseminação da Tecnologia Educacional no Brasil. Revista Educação Unisinos, 20 (2), 201-214.

CERNY, R.; Almeida, J.; \& Ramos, E. (2014, maio/outubro). Formação continuada de professores para a cultura digital. Revista eCurriculum, 12 (2), 1331-1343.

CRUZ, D. (2015). Letramentos e narrativas digitais de professores da educação básica: um estudo de caso da Especialização a distância Educação na Cultura Digital do Proinfo Integrado. Projeto de pesquisa, Florianópolis, UFSC. 
CRUZ, D. (2013). Letramento midiático na educação a distância. In: F. Fidalgo; W. Corradi; R. Souza Lima; A. Favacho; \& E. Arruda. (Org.). Educação a distância: meios, atores e processos. Belo Horizonte: CAED UFMG.

CRUZ JUNIOR, G. (2017). O delinquente em cada um de nós: uma introdução a pedagogia do "mau exemplo" nos videogames. Curitiba: CRV.

FREIRE, P. (1988). A Importância do ato de ler: em três artigos que se completam. São Paulo: Cortez.

HARGREAVES, A. (2001, fevereiro/abril). O ensino como profissão paradoxal. Revista Pátio, 4 (16), 13-18.

LÉVY, P. (1999). Cibercultura. São Paulo: Editora 34.

LOSTADA, L. R.; CRUZ, D. M.. (2017, janeiro/junho). A EAD como um horizonte de novas possibilidades didático-pedagógicas: o caso do Curso de Especialização em Educação na Cultura Digital. POIÉSIS - Revista do Programa de Pós-Graduação em Educação (Unisul), 11 (19), 188-208.

MARTÍN-BARBERO, J. (2004). Ofício de cartógrafo: Travessias latino-americanas da comunicação na cultura. São Paulo: Edições Loyola.

RAMOS, E.; CERNY, R.; et al. (2013). Curso de especialização em educação na cultura digital: documento base. Brasília: Ministério da Educação. 